\title{
Voluntary Testing Practice Among People with Clinical Symptoms of COVID-19 in Somalia: Using Andersen's Behavioral Model
}

\author{
Mohamed Ali Magan, ${ }^{1, *}$, Duah Dwomoh ${ }^{2}$ \\ ${ }^{1}$ Save the Children International, Health Programme Department, Mogadishu, Somalia \\ ${ }^{2}$ Department of Biostatistics, School of Public Health, University of Ghana, Accra, Ghana \\ Email address: \\ Maganyare1@yahoo.com (M. A. Magan), Mohamed.magan@savethechildren.org (M. A. Magan) \\ ${ }^{*}$ Corresponding author \\ To cite this article: \\ Mohamed Ali Magan, Duah Dwomoh. Voluntary Testing Practice Among People with Clinical Symptoms of COVID-19 in Somalia: Using \\ Andersen's Behavioral Model. International Journal of Infectious Diseases and Therapy. Vol. 6, No. 2, 2021, pp. 75-82. \\ doi: $10.11648 /$ j.ijidt.20210602.16
}

Received: June 2, 2021; Accepted: June 21, 2021; Published: June 26, 2021

\begin{abstract}
Background: COVID-19, is a respiratory disease caused by a novel coronavirus. The virus is a global pandemic which threatens children and their rights in countries around the world. Epidemiologists have advocated for a robust testing and contact tracing as a potential solution to balance public health and economic priorities. Using Anderson Behavioral Model, our study aimed to analyze predisposing, Enabling and Need factors associated with VT4C-19 practice in Somalia. Methods: A cross sectional community-based survey were conducted at household level among adults above the age 18 years living in Mogadishu and Garowe cities. The study used multi-stage stratified-cluster sampling method. Out of the Four main towns in Somalia with a designated free National laboratory for COVID-19 testing by the government, the study randomly selected two cities (Mogadishu \& Garowe) using Simple Random Sampling (SRS) Method. The study used univariate analysis and Multivariable Binary Logistic Regression model to control other possible confounders and to give the Andersen Behavioral Modal that were independently associated with voluntary testing for COVID-19 in Somalia. The statistical significance tests were accepted at $p<0.05$. Results: Only $113(6.6 \%)$ out of $(1,708)$ study participants who experienced clinical symptoms of COVID-19 (between 16 March -31 December 2020) voluntarily tested their COVID-19 status. The study found Predisposing factors including gender $(P<0.001)$, marital status $(p<0.05)$, mass media availability $(p<0.05)$, telephone ownership $(p<0.05)$, peer influence $(P<0.001)$ and stigma of COVID-19 positive individuals in the community $(P<0.001)$, and Enabling factors including: place of residence $(p<0.001)$, expense decision maker at household level $(p<0.05)$, insurance status $(p<0.001)$ and access to outreach and health education program $(p<0.05)$, as well as the Need factors including: perceived importance of COVID-19 voluntary test $(p<0.001)$ and chronic diseases status among the study participants $(p<0.05)$ were among the factors associated with the practice of voluntary tests of COVID-19 among the clinically symptomatic individuals in Somalia. Conclusion: The uptake of Voluntary testing for COVID-19 is very low in Somalia. To promote this, health officials and policy makers need to focus on a consistent and culturally sensitive community sensitization programs and bringing the COVID-19 test closer to the communities including rural communities.
\end{abstract}

Keywords: COVID-19, Predisposing, Enabling and Need Factors, Voluntary Testing of COVID-19 Practice

\section{Background}

Coronavirus Disease 2019, an outbreak of respiratory disease caused by a new coronavirus that was first detected in China on 31 December 2019. Since then, the infection has spread across continents and it is classified as a global pandemic by the World
Health Organization [1]. The virus has been named "SARS-CoV-2" and the disease it causes has been named "Coronavirus Disease 2019" (abbreviated "COVID-19"). This recent COVID-19 outbreak has generated an unprecedented public health crisis, with millions of infections and hundreds of thousands of deaths worldwide (Marc Chadeau-Hyam et al., 
2020) [2]. COVID-19 is a global pandemic which threatens children and their rights in countries around the world and exposes them to potentially massive disruption to their healthcare, education, access to basic needs and services like food, protection and social interaction with family members, teachers, peers and communities [3].

As of today, October 25, 2020, there have been 42,512,186 confirmed cases worldwide, and nearly 1,147,301 deaths; United State of America is currently the leading country globally [4]. Africa is among the worst hit countries by the pandemic, as of October $25^{\text {th }}, 2020$, the cases in Africa are reading $1,707,741$ with 41,145 (CFR 2.4\%) [5]. Somalia confirmed its first case of the novel coronavirus (COVID-19) in Mogadishu on $16^{\text {th }}$ March. As of October 31, 2020, 4,229 laboratory-confirmed cases of COVID-19 including 107 (2.5\%) associated deaths have been reported in Somalia [6]. The majority ( $83 \%$ ) of cases are aged between 20 and 60 years, with a median age of 33 (ranging from 1 to 110 years) and 74\% of the confirmed cases have been male.

According to WHO Somalia, out 3,700 cases of coronavirus disease-19 (COVID-19), 191 (5\%) were health care workers, two of whom died (data up to 30 September 2020) [7]. Owing to probable underreporting, weak surveillance systems in hospital settings to report infections in health care workers, stigma associated with testing and self-reporting as infected with COVID-19 and because most cases of COVID-19 present with mild or asymptomatic infection, the reported number of health care workers who contracted COVID-19 may be an underestimate and not represent the actual infection rate in health care workers in the country. Strict COVID-19 social distancing measures have been effective worldwide in reducing the spread of the virus, but this is not a feasible long-term solution given the enormous cost to social and economic wellbeing. This has prompted research on "exit strategies" that would permit activities and economies to remain open while still protecting healthcare resources and reducing viral transmission. Developing reliable models to guide such strategies requires a better understanding of key parameters, leading to calls for information on social and behavioral heterogeneities that impact transmission [8]. Epidemiologists have advocated for robust testing and contact tracing as a potential solution to balance public health and economic priorities, with research suggesting that an optimal system could prevent up to $80 \%$ of all transmission [9].

However, the success of testing and tracing efforts hinges on minimizing the delay between symptom onset and testing and isolation of index cases [10], with a gap of 48 hours or less being critical for reducing the reproductive number [9].

Though willingness of people experiencing symptoms of COVID-19 to participate in testing and tracing programs is likely to be an essential determinant of their efficacy, few studies have examined factors contributing to testing intentions [11, 12]. Somalia which has an estimated total population of more than 12.3 million, (PESS 2014) [13] has so far recorded only 25,722 Voluntary Testing of COVID-19 status with Average Positivity Rate (APR) 12\% [14]. Though the total number of people experiencing clinical symptoms of
COVID-19 is unknown yet, this still indicate only few people are attending for screening and testing services. The reports from the public COVID-19 testing centers indicate that the attendance for COVID-19 tests has been slow until the international travels has been permitted by the Federal government of Somalia (FGS) where mandatory COVID-19 screening tests have been obligated to all international travelers. Though the Somali government with the support from WHO and other health partners in the country had strategically established National Laboratories for COVID-19 with polymerase chain reaction (PCR) tests, treatment and isolation centers in four main cities (Mogadishu, Garowe, Hargeisa and Burao) to serve for the majority of the population, its estimated that less than One Percent $(<1 \%)$ of the respective towns' population attended for voluntary COVID-19 tests. In regard to the services (test) utilization, there has not been a significant difference in the four locations (ranging from $1.22 \%$ in Mogadishu to $0.02 \%$ in Burao) [14].

Emerging evidence suggests that perceptions of infection risk $[15,16]$ desire to avoid infecting others [12] and anticipated financial costs associated with testing, treatment, and quarantining may affect willingness to be tested for COVID-19 [12, 17]. A study on the MERS Coronavirus proved that the people who are more prone to the infection showed better preventive behaviors. The results complied with the theory that suggests the risk perception of infectious diseases promotes proper preventive behaviors, this study also suggested that risk perception can contribute to controlling the spread [18]. According to study carried out among the Rohingya and host community in Cox's Bazar, Bangladesh, reasons provided by patients for declining a test included: 1) fear, 2) the belief that COVID-19 does not exist, that Allah will prevent them from contracting it, or that their symptoms are not caused by COVID-19, 3) no permission from husband/family, and 4) a preference to return at a later time for a test [19].

However, to date, there have been no representative studies of factors affecting COVID-19 voluntary testing intentions among the symptomatic individuals in Somalia. Therefore, this study is seeking to establish associated factors with voluntary testing of COVID-19 status in Somalia by using Andersen's Behavioral model.

\section{Methods}

\subsection{Study Setting}

The study were conducted in Somalia especially in a randomly selected cities of Mogadishu (Abdiaziz, Hamarweyne, Bondhere, Heliwa, Wadajir \& Hamarjajab districts) and Garowe out of the four cities with designated National Laboratories for COVID - 19 (Mogadishu, Garowe, Hargeisa and Burao).

\subsection{Study Design and Sample Size}

A cross sectional community-based survey were conducted at household level among adults above the age 18 years living 
in Mogadishu and Garowe cities. The sample size is estimated as follows:

$$
n=D E F F \times S t r a t a \times \frac{Z_{1-\frac{\alpha}{2}}^{2} P(1-P)}{e^{2} \times(1-N R)}
$$

Where, $n$ is the sample size, $Z$ is standard normal variable at $95 \%$ Confidence Interval (1.96), $\mathrm{P}$ is $(0.5)$ the proportion of population who voluntarily attend for COVID-19 test at the government designed National Lab centers in Somalia, $e$ is the marginal error (0.05), and contingency for non-response (0.10). This study assumes a design effect of 2 . Since we have two communities (rural and urban) and the fact that we are interested in community specific estimates, our final sample size was inflated by a factor of 2 (i.e strata $=2$ ). $N R=10 \%$ is the individual level non-response rate.

Substituting the parameters in equation 1 , the total number of participants required for the study is 1,708 . To determine the number of households required to find 1,708 older adults, we assumed that $53 \%$ of the households would be adults aged $18+$ with an average household size of 6 [13]. The total number of households required is given by

$$
\# \text { Households }=\frac{n}{H_{\text {size }} \times P_{\text {older }(18+)}}
$$

Substituting the parameters $n=1,708$ (number of study participants), $H_{\text {size }}=6$ (the average household size in Somalia) and $P_{\text {older (18+) }}=53 \%$ (the proportion of adults aged 18 years and above), the estimated number of households to be visited by the field interviewers is 538 across the selected regional capitals.

\subsection{Sampling Procedure}

The study used multi-stage stratified-cluster sampling method. Out of the Four main towns with designated free National laboratories for COVID-19 testing by the government of Somalia, the study randomly selected two cities (Mogadishu \& Garowe) using Simple Random Sampling (SRS) Method to ascertain equal chance among the four-target location population. Then the two selected towns were further divided into districts [in Mogadishu] and divisions [in Garowe and Mogadishu districts] and then applied a Simple Random Sampling Method to select 6 out of 17 districts in Mogadishu and 2 out of 4 divisions in Garowe district. Each selected districts/division from each location has been further divided into sections (Laan/Falar) and then Simple Random Sampling method were deployed to select the target Sections. Proportion to household sample were interviewed using systematic sampling method.

\subsection{Inclusion Criteria}

There was a screening question to ask for a previous experience for COVID-19 symptoms between $\left(16^{\text {th }}\right.$ March December 2020). Anyone above the age of 18 years who experienced clinical symptoms of COVID-19 (between 16 March - 31 December 2020) in the household were interviewed purposively with the help of pre-written questionnaire until the sample size of 1,708 respondents is achieved.

\subsection{Measures}

The study used both structured and semi-structured questionnaire to collect the information. Before the data collection process, the enumerators were trained on the questionnaire. The questionnaire was pretested by identifying 20 respondents outside the selected population. The enumerators explained the aim of the interview to the participants and also sought consent from the respondents. The questionnaire was a researcher administered questionnaire. All the participants were interviewed at their convenient places after getting written consent from them. All respondents who do not meet the inclusion criteria were excepted from this study.

\subsection{Statistical Analysis}

The study used KoBo Toolbox to collect the data and then were exported to IBM SPSS Statistics 20 (Statistical Package for social Science) template. Descriptive analysis was made to determine the level of utilization of voluntary testing for COVID-19 among the targeted population. Distribution of the variables were analyzed by using frequency tables. Bivariate analysis was carried out to establish the predisposing, enabling and need factors associated with voluntary testing of COVID-19 among Somalis. The study used Multivariable Binary Logistic Regression model to control other possible confounders and to give the Andersen Behavioral Modal factors that were independently associated with voluntary testing for COVID-19 in Somalia. The statistical significance tests were accepted at $\mathrm{p}<0.05$.

All the methods were carried out in accordance with the relevant guidelines and regulations.

\section{Results}

\subsection{Univariate Analysis of Anderson Behavioral Model Factors}

A complete data was obtained from 1,708 study participants above the age of 18 years who experienced clinical symptoms of COVID-19 (between 16 March - 31 December 2020) in Mogadishu districts and Garowe. Out of the total respondents $(1,708)$, only $113(6.6 \%)$ indicated that they had tested their COVID-19 status voluntarily whereas out of the total voluntarily tested individuals, 50 (44.2\%) of them were tested positive. This indicates that the voluntary testing practice of COVID-19 in Somalia is far below the recommended practice by WHO and government of Somalia for individuals with clinical symptom of the virus to check their status voluntarily. This could also discourage the confidence of early case identification and the overall national and global efforts to promote preventive behaviors and mitigate the community transmission of the virus. According to [Table 1], almost one half, $842(49.3 \%)$ of the respondents were female. Majority of the study participants $727(42.6 \%)$ were in the age category 
between the age 26 and 33 years. more than one half, 1,012 $(59.3 \%)$ of the respondents were at secondary school level and above whereas $375(22 \%)$ had no formal education. 1,023 $(59.9 \%)$ of the study participants were married, followed by 447 (26.2) single. Out of the total respondents, only 230 $(13.5 \%)$ had access to mass medias including the radios/TVs, however, $95.6 \%$ of the respondents had personal phones. 507 (29.7\%) respondents indicated that their peers had an influence on their decisions to either attend or not attend for voluntary testing of COVID-19 at the public facilities. 339 $(19.9 \%)$ of respondents indicated that the health workers discouraged them to attend for COVID-19 tests while they were clinically symptomatic. Majority of the respondents 790 $(46.3 \%)$ were from households with 2-3 members whereas $578(33.8 \%)$ respondents' household members were 5 and above. Almost half, $822(48.1 \%)$ of the respondents mentioned that COVID-19 positive individuals are stigmatized in their respective communities.

Table 1. Background Characteristics of the study participants $(n=1,708)$ Mogadishu and Garowe, Somalia March 2021.

\begin{tabular}{|c|c|c|}
\hline Characteristics & Frequency & Percentage $(\%)$ \\
\hline \multicolumn{3}{|c|}{ Gender of the respondents } \\
\hline Female & 842 & 49.3 \\
\hline Male & 866 & 50.7 \\
\hline \multicolumn{3}{|l|}{ Age of the respondents } \\
\hline $18-25$ years & 409 & 23.9 \\
\hline $26-33$ years & 727 & 42.6 \\
\hline $34-41$ years & 391 & 22.9 \\
\hline 42 years and above & 181 & 10.6 \\
\hline \multicolumn{3}{|c|}{ Education level of the respondents } \\
\hline No Formal Education & 375 & 22.0 \\
\hline Primary Education & 321 & 18.8 \\
\hline Secondary /and above & 1012 & 59.3 \\
\hline \multicolumn{3}{|c|}{ Marital status of the respondents } \\
\hline Divorced & 154 & 9.0 \\
\hline Married & 1023 & 59.9 \\
\hline Separated & 7 & 0.4 \\
\hline Single & 447 & 26.2 \\
\hline Widowed & 77 & 4.5 \\
\hline \multicolumn{3}{|c|}{ Telephone ownership (Personal) } \\
\hline No & 76 & 4.4 \\
\hline Yes & 1632 & 95.6 \\
\hline \multicolumn{3}{|c|}{ Household characteristics/composition } \\
\hline $1-2$ individuals & 340 & 19.9 \\
\hline $3-4$ individuals & 790 & 46.3 \\
\hline 5 and or above & 578 & 33.8 \\
\hline \multicolumn{3}{|l|}{ Place of residence } \\
\hline Rural & 34 & 2.0 \\
\hline Urban & 1674 & 98.0 \\
\hline \multicolumn{3}{|c|}{ Insurance status of the respondents } \\
\hline Ensured & 112 & $7 \%$ \\
\hline Not insured & 1596 & $93 \%$ \\
\hline
\end{tabular}

Majority of the study participants 1,674 (98\%) were from urban. $804(47.1 \%)$ of the total respondents lived less than 5 kilometers from the public testing centers, followed by 677 (39.6\%) lived between $5-10$ kilometers away from the public testing centers [see Table 1]. Majority of the respondents $1,328(77.8 \%)$ indicated that only one member contributes to the monthly household income whereas only $62(3.6 \%)$ indicated more than three sources of income for the monthly household income. Almost one half, 794 (46.5\%) of the study participants indicated low monthly household income (Less than 1.9 USD per person per day). Majority of the households visited, 1,435 (84\%) were male headed households, whereas $882(51.6 \%)$ of the respondents indicated that the husband was the household expense decision maker. Majority of the participants 1,596 (93.4\%) were not under health insurance coverage (not insured) [see Table 1]. Out of 113 respondents who attended for COVID-19 test at the testing facilities, majority 42 (37\%) indicated waiting time for getting COVID-19 test of less than 15 minutes, however, 36 (32\%) indicated waiting time of more than 30 minutes to get tested. Out 113 participants indicated to have gone for COVID-19 tests, $88(77.9 \%)$ experienced overcrowd at the service facilities. Almost two-third of the respondents, 1,049 (61.4) had no access to outreach or health education programs. Majority of the study participants, 1,359 (79.6\%) had awareness on the COVID-19 complications including the mortality and morbidities related to the virus. However, 511 $(29.9 \%)$ of the respondents did not perceive the importance of COVID-19 tests for individuals with clinical symptoms. Equal number of respondents 571 (33.4\%) perceived the severity of COVID-19 as moderate or severe whereas 567 (33.2\%) of the respondents perceive the virus as a normal/ no more harm for the individuals. Majority of the study participants 1,344 $(78.7 \%)$ of the respondents did not have chronic diseases. 184 $(10.8 \%)$ out of the total study participants were disabled.

\subsection{Anderson Behavioral Model Factors Associated with Voluntary Testing for COVID-19 Practice (VT4C-19)}

In this study [see Table 2], we assessed the factors associated with voluntary testing practice among people with Clinical Symptoms of COVID-19 in Somalia. To control the possible confounder variables and identify the real predictor variables (Anderson's Behavioral Model factors) associated with the dependent variable, the study used Multivariable Binary Logistic Regression model. The odds of Voluntary Testing for COVID-19 Practice (VT4C-19 practice) for men was $30 \%$ less (AOR 0.3; 95\% CI: 0.2, 0.5, p<0.001) compared to its counterpart, 4.7-fold among the widowed compared to their counterparts of married and separated, AOR $(95 \% \mathrm{CI})$ : $2.1(0.4,9.9)$ and AOR $(95 \% \mathrm{CI}): 2.1(0.5,8.6)$ respectively. The Odds of VT4C-19 practice for those participants with available mass media was 2 times higher than those with no available mass media (AOR 2.0; 95\% CI: 1.3, 3.2, $\mathrm{p}<0.05$ ). the Odds of VT4C-19 practice was 2.5 times higher among the personal telephone owners than their counterparts without personal telephones (AOR 2.5; 95\% CI: 1.3, 5.0, $p<0.05$ ). The Odds of VT4C-19 practice was $42 \%$ less among those influenced by their peers than those with no peer influence (AOR $0.4 ; 95 \% \mathrm{CI}: 0.3,0.6, \mathrm{p}<0.01$ ). the study found that the Odds VT4C-19 practice was $40 \%$ less among those discouraged by the health workers compared to their counterparts (not discouraged by the health workers) (AOR $0.4 ; 95 \%$ CI: $0.3,0.6, \mathrm{p}<0.01)$. The Odds of VT4C-19 practice was $53 \%$ less among those participants with 5 and above household members (AOR 0.5; 95\% CI: 0.3, 0.8, p<0.05) than 
their counterpart with 3-4 household members AOR (95\% CI): $0.9(0.6,1.5)$. The Odds of VT4C-19 practice was $38 \%$ less among those participants with those communities who stigmatize the COVID-19 cases (AOR 0.4; 95\% CI: 0.3, 0.6, $\mathrm{p}<0.01)$ than those with no stigmatizing communities. Predisposing factors like the age of the respondents and education level did not reveal statistically significant association ( $p>0.05$ with VT4C-19 practice of the study participants.

The Odds of VT4C-19 practice for urban resident participants was 7 times higher (AOR 7.4; 95\% CI: 3.5, 15.5, $\mathrm{p}<0.01)$ compared to Rural residents [Table 2]. The Odds VT4C-19 practice for Households (HH) with 2 sources of $\mathrm{HH}$ income was 33\% less (AOR 0.3; 95\% CI: 0.2, 0.7, p<0.05) compared to participants with 3 or more $\mathrm{HH}$ sources of income AOR $(95 \% \mathrm{CI}): 0.7(0.3,1.6)$. The Odds of VT4C-19 practice for study participants from HHs with wife expense decision maker was 2.4 times higher (AOR 2.4; 95\% CI: 1.2 , $4.9, \mathrm{p}<0.05)$ compared to those with husbands or both. The Odds of VT4C-19 practice for insured study participants was
7.5 fold higher (AOR 7.5; 95\% CI: 4.7, 11.9, p<0.01) compared to non-insured study participants, however, the study found the Odds of VT4C-19 practice for study participants with access to outreach and/or health education programs was $50 \%$ less (AOR 0.5; 95\% CI: 0.4, 0.8, p<0.05) compared to those with no access to outreach and/or health education programs. Enabling factors including distance from the testing centers and head of the households did not reveal statistically significant association ( $p>0.05$ with VT4C-19 practice of the study participants.

The Odds of VT4C-19 practice for participants who perceived the importance of COVID-19 voluntary Test was 12.7-fold higher (AOR 12.7; 95\% CI: 4.7, 34.6), $\mathrm{p}<0.01$ ) compared to those who did not perceive. The Odds of VT4C-19 practice for participants with chronic diseases $58 \%$ less (AOR 0.58; 95\% CI: 0.4, 0.9, p<0.05) compared to those with chronic diseases. Need factors including awareness of the COVID-19 complications, illness severity and the disability did not reveal statistically significant association ( $p>0.05$ with VT4C-19 practice of the study participants.

Table 2. Multivariate Logistic regression analysis of Anderson's behavioral Modal and Voluntary Testing Practice Among People with Clinical Symptoms of COVID-19 in Somalia, April, 2021.

\begin{tabular}{|c|c|c|c|c|c|}
\hline \multirow{2}{*}{ Variable } & \multicolumn{5}{|c|}{ Have you tested your C-19 status voluntarily? } \\
\hline & No $(\%)$ & Yes $(\%)$ & $\operatorname{COR}(95 \% \mathrm{CI})$ & AOR (95\% CI) & $P$ - value \\
\hline \multicolumn{6}{|c|}{ Gender of the respondents } \\
\hline Female & $815(97 \%)$ & $27(3 \%)$ & 1 & 1 & \\
\hline Male & $780(90 \%)$ & $86(10 \%)$ & $0.291(0.181,0.467)$ & $0.300(.193,0.468)$ & 0.000 \\
\hline \multicolumn{6}{|l|}{ Age of the respondents } \\
\hline $18-25$ years & $378(92 \%)$ & $31(8 \%)$ & 1 & 1 & \\
\hline $26-33$ years & $681(94 \%)$ & $46(6 \%)$ & $0.742(0.287,1.921)$ & $1.402(0.672,2.926)$ & 0.367 \\
\hline $34-41$ years & $365(93 \%)$ & $26(7 \%)$ & $1.034(0.441,2.428)$ & $1.155(0.571,2.336)$ & 0.688 \\
\hline 42 years and above & $171(94 \%)$ & $10(6 \%)$ & $1.474(0.628,3.462)$ & $1.218(0.574,2.583)$ & 0.607 \\
\hline \multicolumn{6}{|l|}{ Education level } \\
\hline No Formal Education & $353(94 \%)$ & $22(6 \%)$ & 1 & 1 & \\
\hline Primary Education & $305(95 \%)$ & $16(5 \%)$ & $0.558(0.308,1.010)$ & $0.779(0.477,1.272)$ & 0.318 \\
\hline Secondary /and above & $937(93 \%)$ & $75(7 \%)$ & $0.959(0.534,1.720)$ & $0.655(0.376,1.142)$ & 0.136 \\
\hline \multicolumn{6}{|l|}{ Marital status } \\
\hline Divorced & $146(95 \%)$ & $8(5 \%)$ & 1 & 1 & \\
\hline Married & $970(95 \%)$ & $53(5 \%)$ & $2.214(0.420,11.677)$ & $2.055(.426,9.919)$ & 0.370 \\
\hline Separated & $7(100 \%)$ & $0(0 \%)$ & $1.876(0.413,8.524)$ & $2.049(0.490,8.572$ & 0.326 \\
\hline Single & $397(89 \%)$ & $50(11 \%)$ & $0.000(0.000-)$ & $0.000(0.000,-)$ & 0.999 \\
\hline Widowed & $75(97 \%)$ & $2(3 \%)$ & $4.190(0.860,20.416)$ & $4.723(1.125,19.829)$ & 0.034 \\
\hline \multicolumn{6}{|l|}{ Mass media availability } \\
\hline No & $204(89 \%)$ & $26(11 \%)$ & 1 & 1 & \\
\hline Yes & $1391(94 \%)$ & $87(6 \%)$ & $2.403(1.351,4.276)$ & $2.038(1.284,3.235)$ & 0.003 \\
\hline \multicolumn{6}{|l|}{ Telephone ownership } \\
\hline No & $65(86 \%)$ & $11(14 \%)$ & 1 & 1 & \\
\hline Yes & $1530(94 \%)$ & $102(6 \%)$ & $2.403(1.351,4.276)$ & $2.538(1.299,4.959)$ & 0.006 \\
\hline \multicolumn{6}{|l|}{ Peer influence } \\
\hline No & $1143(95 \%)$ & $58(5 \%)$ & 1 & 1 & \\
\hline Yes & $452(89 \%)$ & $55(11 \%)$ & $0.573(0.375,0.876)$ & $0.417(0.284,0.613)$ & 0.000 \\
\hline \multicolumn{6}{|c|}{ Discouragement from the Health Workers } \\
\hline No & $1297(95 \%)$ & $72(5 \%)$ & 1 & 1 & \\
\hline Yes & $298(885)$ & $41(12 \%)$ & $0.591(.375, .932)$ & $0.403(.269,0.604)$ & 0.000 \\
\hline \multicolumn{6}{|c|}{ Household characteristics/composition } \\
\hline $1-2$ individuals & $313(92 \%)$ & $27(8 \%)$ & 1 & 1 & \\
\hline 3-4 individuals & $753(95 \%)$ & $37(55)$ & $0.795(0.456,1.385)$ & $0.931(0.570,1.520)$ & 0.776 \\
\hline 5 and or above & $529(92 \%)$ & $49(8 \%)$ & $0.528(0.325,0.859)$ & $0.530(0.341,0.825)$ & 0.005 \\
\hline \multicolumn{6}{|c|}{ In your community, is people with COVID-19 positive stigmatized? } \\
\hline No & $852(96 \%)$ & $34(4 \%)$ & 1 & 1 & \\
\hline Yes & $743(90 \%)$ & $79(105)$ & $0.504(0.317,0.800)$ & $0.375(0.248,0.568)$ & 0.000 \\
\hline \multicolumn{6}{|c|}{ Place of residence of the respondents } \\
\hline Rural & $23(68 \%)$ & $11(32 \%)$ & 1 & 1 & \\
\hline
\end{tabular}




\begin{tabular}{|c|c|c|c|c|c|}
\hline \multirow{2}{*}{ Variable } & \multicolumn{5}{|c|}{ Have you tested your C-19 status voluntarily? } \\
\hline & No (\%) & Yes (\%) & COR $(95 \% \mathrm{CI})$ & AOR $(95 \%$ CI) & P-value \\
\hline Urban & $1572(94 \%)$ & $102(6 \%)$ & $3.819(1.532,9.520)$ & $7.371(3.496,15.540)$ & 0.000 \\
\hline \multicolumn{6}{|c|}{ Distance from the public testing centers } \\
\hline Less than $5 \mathrm{KM}$ & $740(92 \%)$ & $64(8 \%)$ & 1 & 1 & \\
\hline $5-10 \mathrm{KM}$ & $647(96 \%)$ & $30(4 \%)$ & $0.664(0.415,1.062)$ & $0.536(0.343,0.838)$ & 0.006 \\
\hline Above $11 \mathrm{KM}$ & $208(92 \%)$ & $19(8 \%)$ & $1.585(0.821,3.062)$ & $1.056(0.619,1.803)$ & 0.841 \\
\hline \multicolumn{6}{|c|}{ Number of HH members contribute to monthly household income } \\
\hline 1 source & $1258(95 \%)$ & $70(5 \%)$ & 1 & 1 & \\
\hline 2 sources & $284(89 \%$ & $34(115)$ & $0.943(0.407,2.184)$ & $0.328(0.155,0.691)$ & 0.003 \\
\hline 3 or more & $53(85 \%)$ & $9(15 \%)$ & $1.232(0.517,2.934)$ & $0.705(0.320,1.555)$ & 0.386 \\
\hline \multicolumn{6}{|l|}{ Head of the households } \\
\hline Child headed HH & $16(100 \%)$ & $0(0 \%)$ & 1 & 1 & \\
\hline Female headed HH & $246(96 \%)$ & $11(4 \%)$ & $0.000(0.000-)$ & $0.000(0.000,-)$ & 0.999 \\
\hline Male headed HH & $1333(93 \%)$ & $102(7 \%)$ & $0.667(0.310,1.432)$ & $0.584(0.309,1.105)$ & 0.098 \\
\hline \multicolumn{6}{|c|}{ Expense decision maker at household level } \\
\hline Both Husband and wife & $528(94 \%)$ & $35(6 \%)$ & 1 & 1 & \\
\hline The husband & $813(92 \%)$ & $69(8 \%)$ & $1.432(0.607,3.376)$ & $1.871(0.886,3.951)$ & 0.101 \\
\hline Wife & $254(97 \%)$ & $9(3 \%)$ & $1.465(0.634,3.387)$ & $2.395(1.179,4.866)$ & 0.016 \\
\hline \multicolumn{6}{|c|}{ Insurance status of the respondents } \\
\hline Not insured & $1515(95 \%)$ & $81(5 \%)$ & 1 & 1 & \\
\hline Ensured & $80(71 \%)$ & $32(29 \%)$ & $3.094(1.781,5.377)$ & $7.481(4.690,11.934)$ & 00.000 \\
\hline \multicolumn{6}{|c|}{ Outreach and health education programs } \\
\hline No & $997(95 \%)$ & $52(5 \%)$ & 1 & 1 & \\
\hline Yes & $598(91 \%)$ & $61(9 \%)$ & $0.619(0.415,0.923)$ & $0.511(0.348,0.750)$ & 0.001 \\
\hline \multicolumn{6}{|c|}{ Awareness of C-19 complications } \\
\hline No & $322(92 \%)$ & $27(8 \%)$ & 1 & 1 & \\
\hline Yes & $1273(94 \%)$ & $86(6 \%)$ & $1.954(1.196,3.191)$ & $1.241(0.792,1.945)$ & 0.346 \\
\hline \multicolumn{6}{|c|}{ Perceived importance of C-19 voluntary tests } \\
\hline Not important & $507(99 \%)$ & $4(1 \%)$ & 1 & 1 & \\
\hline Important & $1088(91 \%)$ & $109(9 \%)$ & $22.59(7.902,64.588)$ & $12.69(4.656,34.633)$ & 0.000 \\
\hline \multicolumn{6}{|l|}{ Illness severity } \\
\hline Moderate & $517(91 \%)$ & $54(9 \%)$ & 1 & 1 & \\
\hline Normal & $535(94 \%)$ & $32(6 \%)$ & $2.346(1.450,3.795)$ & $2.101(1.303,3.386)$ & 0.002 \\
\hline Severe & $543(95 \%)$ & $27(5 \%)$ & $2.985(1.701,5.237)$ & $1.203(0.711,2.035)$ & 0.491 \\
\hline \multicolumn{6}{|c|}{ Chronic diseases (i.e. Diabetic and or hypertension) } \\
\hline No & $1266(94 \%)$ & $78(6 \%)$ & 1 & 1 & \\
\hline Yes & $329(90 \%)$ & $35(10 \%)$ & $0.797(0.514,1.234)$ & $0.579(0.382,0.879)$ & 0.010 \\
\hline \multicolumn{6}{|c|}{ Disability among the respondents } \\
\hline No & $1427(94 \%)$ & $97(6 \%)$ & 1 & 1 & \\
\hline Yes & $168(91 \%)$ & $16(9 \%)$ & $0.773(0.432,1.382)$ & $0.714(0.411,1.240)$ & 0.232 \\
\hline
\end{tabular}

\section{Discussion}

In this study, it was found that only $6.6 \%$ of the total $(1,708)$ study participants who experienced clinical symptoms of COVID-19 (between 16 March - 31 December 2020) tested their COVID-19 status voluntarily, of which 50 (44.2\%) of them were tested positive. This shows the voluntary testing practice among the clinically symptomatic individuals is very low in Somalia, and the positivity rate established by this study $(44.2 \%)$ is much higher than average daily reports of the Federal Ministry of Health, Somalia which shows an Average Positivity Rate (APR) of $12 \%$ [14]. This difference could be explained by the difference in the methodology and the inclusion criteria of this study which was mainly focusing on those experienced the clinical symptoms of COVID-19 for the specified period of time. $51 \%$ of the study participants were male, the study found that males had $30 \%$ less chance to carryout VT4C-19 practice compared to women $(\mathrm{p}<0.05)$. This indicates that Somali men are more hesitant in health seeking behaviors compared to women. In this study we found that $95.6 \%$ of the study participants had personal mobile phones. The study found that the uptake of VT4C-19 was 2.5 times higher among the personal phone holders compared to non-phone holders. The free COVID-19 messages aired by the local telecommunications could explain the utilization differences among the two groups. Because of limited related studies, there were no previous studies to compare and contrast with this study finding.

$20 \%$ of the study participants indicated that they were discouraged from attending voluntary testing of COVID-19 by health workers. The study revealed that VT4C-19 was $40 \%$ less among those were discouraged by the health workers compared to their counterparts. This could be that the health workers themselves do not have adequate information and training on the pandemic and its complications as this would help them to give right information to the community for right decision making. Training health workers would also help them have wealth information on the virus as this would help them have the ability to promote the key messages on COVID-19 including the importance of early testing practice, respond to FAQs from the community on the virus risks and mitigation measures. Stigmatization of the COVID-19 positive cases among the community were strongly associated with the poor 
uptake of VT4C-19 among the Somalia community. 822 (48\%) of the study participants indicated that their communities stigmatize COVID-19 positive cases, the study also found that the uptake was $37 \%$ less among those participants from these communities compared to those do not-discriminate. This study agrees with a study carried out in Rohingya and host community in Cox's Bazar, Bangladesh, which indicated that patients were declining for the test because of fear [19].

The study found out the uptake of VT4C-19 was 32\% higher among the rural residents compared to only $6 \%$ among the urban residents and this association was significant at $(P \leq$ $0.05)$. Though, the public testing centers has been designated only for big cities, this could explain that if the service could have been taken nearer to the rural populations, the uptake could have been in a better shape than its current status in Somalia. The uptake of VT4C-19 was 2.4 times higher among those participants from households with wife expense decision maker compared to those with husband decision maker. This finding stresses this same study finding above which is showing that male was $30 \%$ less chance of VT4C-19 practice compared to women $(P \leq 0.05)$. The study also complements another study carried out among Rohingya and host community in Cox's Bazar, Bangladesh which showed that lack of permission from husband/family was among the main reasons that patients were declining to undergo the VT4C-19 [19]. According to the study finding, insurance status of the of study participants was associated with VT4C-19 practice. The insured participants were 7.5 times higher in the utilization of the VT4C-19 compared to Non-insured study participants. This could explain that big number of the population are not attending for the services because anticipated financial costs associated with the testing since they have no insurance coverage. This study agrees with another study carried at by (Brea L. Perrya et al., in May 2020) which showed that anticipated financial costs associated with test was one of the main reasons for not undertaking the tests $[12,17] .70 \%$ of the study participants perceived the importance of COVID-19 voluntary tests. The VT4C-19 uptake was 12.7 times higher among those who perceived the importance of voluntary tests compared to those who don't ( $P$ $\leq$ 0.05). This indicates the higher the awareness on the voluntary testing among the study participants, the better the utilization. This study agrees with Thunström L, et al., 2020 study which showed that the desire to avoid infecting others was significantly associated with the testing [12]. 364 (21.3\%) of this study participants had chronic diseases (i.e. diabetic and or hypertension), however, the study found that the VT4C-19 practice was 58\% less among those with chronic diseases. Ideally, the people with chronic diseases are expected to exercise better preventive behaviors, however, it's not clear the reasons for this conflicting practice. This study disagrees with the study on the MERS Coronavirus which proved that the people who are more prone to the infection showed better preventive behaviors [18]. The difference could be explained by the low level of community awareness specially among the elderly Somali community who seem to be more traditional than the youth and middle age people.

\section{Limitations of the Study}

During the start of the study, only four cities in Somalia had Public Laboratories for COVID - 19 to offer free services (Mogadishu, Garowe, Hargeisa and Burao), and the study Randomly selected two cities (Mogadishu and Garowe), however, in the course of the study, several other Public Laboratories for COVID - 19 were delivered to main cities in the country including Baledweyne, Kismayo and Baidoa and there was no chance for the researcher to revisit the study area, expand the list and apply random selection again. This may affect the perfect representation of this study.

\section{Conclusions and Recommendation}

The study showed that the uptake of VT4C-19 practice among those experienced clinical symptoms was only $6.6 \%$, which is indicating a very low practice of the preventive behavior among the Somalis. Predisposing factors including gender, marital status, mass media availability, telephone ownership, peer influence and stigma, and enabling factors including: place of residence, expense decision maker at household level, insurance status and access to outreach and health education program, as well as the need factors including: perceived importance of COVID-19 voluntary test and chronic diseases status among the study participants were among the factors associated with the practice of voluntary tests of COVID-19 among the clinically symptomatic individuals in Somalia. Thus, consistent and culturally sensitive community sensitization programs (through the media, public figures including religious leaders and the Ugaas - clan leaders) and bringing services (lab tests) closer to the community, women empowerment and economic enhancing interventions are crucial interventions to improve this behavior and promote better preventive behaviors including early testing practice of COVID-19.

\section{Declarations}

\section{Ethics Approval and Consent to Participate}

Ethical clearance was obtained from the Research and Ethics Committee at the Federal Ministry of Health (R\&E FMOH) and the Puntland State Ministry of Health Research Committee. Since the data collectors/enumerators used Kobo Collect platform, verbal consent was obtained from all the participants in the study before the interview as per the instruction of the Research and Ethics Committee at the Federal Ministry of Health (R\&E FMOH). The participants were interviewed individually at their convenient places and the questionnaire were made anonymous. The enumerators were introduced themselves to the study participants and explained the aim and the content of the questionnaire; the respondents were given an option that they could withdraw from process at any point in time.

\section{Availability of Data and Materials}

Data is available on request from the corresponding author. 


\section{Competing Interests}

The authors declare that they have no competing interests.

\section{Funding}

None.

\section{Authors' Contributions}

Mohamed Ali Magan conceptualized the study, study design, developed the questionnaire, analyzed and interpreted the data and drafted the manuscript report. Duah Dwomoh technical advice on the methodology development, critically reviewed and improved the manuscript. All the authors greatly contributed to the study and approved the final version of the manuscript.

\section{Acknowledgements}

We would like to express our deepest gratitude to all the study participants for their voluntary participation. Same gratitude goes to the research assistants from Somalia National University (SNU) and East University in Garowe, Somalia for their support. Finally, the research coordinator Dr Mohamed Abdirahman Abdi.

\section{References}

[1] World Health Organization. WHO Director-General's opening remarks at the media briefing on COVID-19. Geneva: World Health Organization; 2020.

[2] Marc Chadeau-Hyam et al., Risk factors for positive and negative COVID-19 tests: a cautious and in-depth analysis of UK biobank data; International Journal of Epidemiology, 2020, $1-14$.

[3] Save the Children's COVID-19 Program Framework and Guidance: version: 2, March 2020.

[4] WHO Coronavirus Disease (COVID-19) Dashboard: Data last updated: 2020/10/25, 2:09 pm CET.

[5] Africa CDC Dashboard: Coronavirus Disease 2019 (COVID-19); Data received on: 2020/10/25, 7:54:09 pm EAT.

[6] Jointly published by the Ministry of Health and Human Services, Federal Government of Somalia and WHO Somalia Country Office: COVID-19 Situation Report; Issue 34 (25 - 31 OCTOBER 2020).
[7] World Health Organization: COVID-19 in health workers in Somalia: concerning, but more data are needed. COVID-19 information note 7 - October 2020.

[8] Thompson RN, Hollingsworth TD, Isham V, et al. Key questions for modelling COVID-19 exit strategies. Proceedings of the Royal Society B. 2020; 287 (1932): 20201405.

[9] Kretzschmar ME, Rozhnova G, Bootsma MC, van Boven M, van de Wijgert JH, Bonten MJ. Impact of delays on effectiveness of contact tracing strategies for COVID-19: a modelling study. The Lancet Public Health. 2020; 5 (8): e452e459.

[10] Quilty BJ, Clifford S, Flasche S, Kucharski AJ, Edmunds WJ, Group CC-19 W. Quarantine and testing strategies in contact tracing for SARS-CoV-2. medRxiv. Published online 2020.

[11] Fabella FE. Factors Affecting Willingness to be Tested for COVID-19. Available at SSRN 3670514. Published online 2020.

[12] Thunström L, Ashworth M, Shogren JF, Newbold S, Finnoff D. Testing for COVID-19: Willful ignorance or selfless behavior? Behavioural Public Policy. Published online 2020: 1-26.

[13] UNFPA, along with the statistical offices within the Ministries of Planning: Population Estimation Survey of Somalia (PESS) (2014).

[14] Ministry of Health and Human Services, Federal Government of Somalia (HMIS department): screening status in the country (11 ${ }^{\text {th }}$ November 2020).

[15] Bordalo P, Coffman KB, Gennaioli N, Shleifer A. Older People Are Less Pessimistic about the Health Risks of COVID-19. National Bureau of Economic Research; 2020.

[16] de Bruin WB, Bennett D. Relationships Between Initial COVID-19 Risk Perceptions and Protective Health Behaviors: A National Survey. American Journal of Preventive Medicine. Published online 2020.

[17] Labor UD of. Families first coronavirus response act: Employee paid leave rights. Published online 2020.

[18] Brewer NT, et al. Risk perceptions and their relation to risk behavior. Ann Behav Med. 2004; 27 (2): 125-30.

[19] McGowan, C. R., Hellman, N., Chowdhury, S. et al. COVID-19 testing acceptability and uptake amongst the Rohingya and host community in Camp 21, Teknaf, Bangladesh. Confl Health 14, 74 (2020). https://doi.org/10.1186/s13031-02000322-9. 